[ALINE LOPES ROCHEDO]

Jornalista e antropóloga. Doutoranda em antropologia social na UFRGS. Pesquisadora nos grupos Antropologia da Economia e da Política e História da Arte e Cultura de Moda, ambos ligados à UFRGS.

E-mail: alinerochedo@gmail.com

\title{
Fashion Victims: The Pleasures and Perils of Dress in the 19th Century
}

Curadoria: Elizabeth Semmelhacke Alison Matthews David. Local e período: Bata Shoe Museum (BSM), Toronto (Canadá). De junho de 2014 a abril de 2018. 


\section{Prazeres e perigos da moda}

Uma narrativa crítica sobre moda, economia, política, moral e estética que contempla produção e consumo, passado e presente, prazer e perigo. Assim é Fashion Victims: The Pleasures and Perils of Dress in the 19th Century (Vitimas da moda: os prazeres e perigos do vestuário no século XIX), exposição temporária instalada em junho de 2014 no Bata Shoe Museum (BSM), em Toronto, Canadá. Organizada por Elizabeth Semmelhack, curadora do museu, e Alison Matthews David, professora de História de Têxteis e Vestuário da The School of Fashion da Ryerson University, a mostra se encerraria em junho de 2016, mas foi estendida até abril de 2018. Graças à prorrogação, tive a oportunidade de vê-la em maio de 2017.

Na verdade, não fui ao BSM por causa da Fashion Victims. Minha curiosidade, na ocasião, dirigia-se ao acervo de calçados - são cerca de 13 mil itens para contar mais de quatro mil anos de história -, ao prédio assinado pelo arquiteto canadense Raymond Moriyama e às peças de vestuário autóctone da região Ártica. Após quase duas horas circulando pelo museu, cheguei ao terceiro andar, onde está instalada a exposição sobre as vítimas da moda do século XIX.

279 Na entrada, fitei um cavalheiro elegantemente trajado (Figura 1). Tratava-se de um dos personagens de um mural instalado no meio de um salão revestido de madeira, com nichos laterais protegidos por vidros contendo artefatos diversos e lembrando vitrines de lojas de departamento nos moldes franceses e ingleses. Atmosfera sóbria, elegante, sofisticada, para poucos, como se diz. Em uma das mãos, junto ao corpo, a figura masculina do cartaz segurava uma cartola, acessório fundamental para os bem-vestidos daquele século. Já uma mulher, à direita, aparecia impecavelmente vestida, porém prostrada numa cadeira, expressando fadiga e desalento.

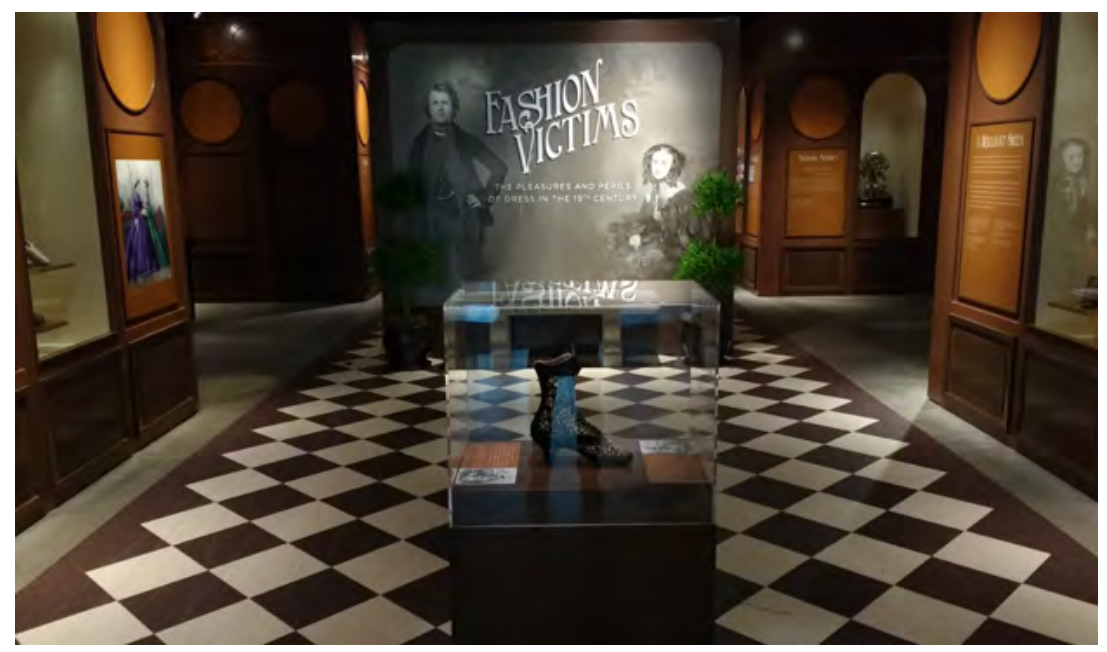

Figura 1: A bota Pinet e o mural antecipam os paradoxos da exposição do BSM.

Foto: Aline Lopes Rochedo. 
Avancei sobre o piso quadriculado e me posicionei diante de um pé de bota feminina produzida à mão pela empresa de Jean-Louis François Pinet (1817-1897), renomado fabricante de calçados de luxo da França do fim do século XIX. Exposta numa caixa de vidro, a peça exibe a riqueza de bordados feitos por mulheres que trabalhavam longas jornadas em suas casas traçando coloridos motivos florais com linhas e agulhas e que recebiam poucos trocados pela tarefa. Jamais era o suficiente para comprar os objetos que ajudavam a embelezar. Tendo seu nome na etiqueta, o patrão Pinet lucrava com a fama e o dinheiro.

Por meio de 90 artefatos acompanhados de textos didáticos e trechos de obras literárias, visitantes percorrem fenômenos socioculturais pautados pela atmosfera perniciosa que enfeitava elites ao mesmo tempo que contaminava centros urbanos europeus em expansão e irradiava, além-mar, discursos de progresso, modernidade e evolução social e industrial. Calçados, roupas, acessórios e anúncios publicitários, cada item conecta um fragmento à reflexão sobre a engrenagem fabril de um contexto de produção massificada de bens de consumo catalisado pela Revolução Industrial em suas diferentes fases.

Em uma das maiores vitrines do salão, há um manequim portando um vestido verde, "inglês ou francês" (a imprecisão consta do texto explicativo), de meados do século XIX. Para compreender o destaque concedido a este e a outros itens de cores vibrantes, é preciso considerar técnicas remotas: o corante verde, por exemplo, foi inventado no fim do século XVIII pelo químico alemão Carl Scheele (1742-1786) ao juntar arsênico e cobre numa combinação funesta. No início do século XIX, caiu nas graças das elegantes saudosas de referências bucólicas e cansadas do excesso de cinza dos esfumaçados centros fabris. Homens e crianças também não resistiam à paleta variada. Naquela época, porém, médicos já alertavam a população para a toxicidade das anilinas, pois eram frequentes irritações de pele e olhos, delírios e até morte de quem trajava, tocava e manufaturava roupas, brinquedos e peças decorativas feitos com o corante. Os danos não poupavam nem pobres, nem ricos, nem consumidores, nem produtores. Mas a ânsia para parecer elegante, entre os que podiam pagar, ou a necessidade de trabalhar para sobreviver, se sobrepunha à saúde.

Não menos popular em indumentária e enfeites foi o corante roxo criado pelo britânico William Perkins (1838-1907) na sua empreitada pela cura da malária e que continha alcatrão mineral, outro ingrediente nocivo. Conforme a curadoria da exposição, testes encomendados a laboratórios universitários indicaram a presença, ainda hoje, de todas essas substâncias em vários artefatos expostos.

A moda masculina passava longe de ser inofensiva, embora a associação aos perigos fosse, já naqueles dias, dirigida ao consumo feminino, parecendo brotar de um "desejo irracional" (MATHEWS DAVID, 2015). 0 processo de confecção das cartolas, por exemplo, levava mercúrio, elemento que, além 
de poluir o ambiente, provocava tremedeira, sede, perda dentária e confusão mental, entre outros males, em pessoas que faziam as peças. Dai a inspiração do escritor Lewis Carroll para criar o personagem Chapeleiro Maluco, de Alice no Pais das Maravilhas, como tão bem relata a exposição.

Ao lado desses e de outros riscos, há crinolinas altamente inflamáveis que contribuiram para a morte por queimadura de pelo menos 300 mulheres por ano no Reino Unido - quando estas esbarravam as saias em velas e lareiras -, e espartilhos, além de, sapatos e botas, tão apertados a ponto de modificar contornos do corpo e provocar tonturas, desmaios e quedas. E o que dizer da substituição do casco de tartaruga em adornos de cabeça para mulheres pelo celuloide, mais barato, mas que entrava em combustão em contato com qualquer fonte de calor? Ou das botas masculinas polidas por crianças que manipulavam - e se envenenavam com - graxas tóxicas e ficavam à mercê da exploração de sua mão de obra barata? Sem falar nos acidentes provocados por saltos.

Percorrendo a exposição, o visitante atento capta a ideia de que o consumo galopante e acelerado no período vitoriano espelhava modos de produção, vaidades e jornadas exaustivas. Cito, por exemplo, uma ilustração de John Tenniel intitulada Ghost in the looking-glass (Fantasma no espelho, tradução minha). Na figura, uma mulher se deleita com sua elegância e observa a dedicada costureira morta no reflexo. Trata-se de uma referência a um incidente ocorrido em meados do século XIX, quando Mary Ann Walkley faleceu aos 20 anos depois de costurar por 26 horas e meia sem parar (MATTHEWS DAVID, 2015).

Ao embaralhar luxo, ciência, saúde e poder, dessa forma, Fashion Victims conecta prazeres e perigos e proporciona um conjunto de inquietações sobre múltiplas relações sociais entre pessoas, espaços de circulação e cultura material. A narrativa da mostra culmina numa sala cuja expografia parece inacabada em relação aos ambientes ocupados por objetos luxuosos e por suas versões massificadas e populares, porém belas e desejadas. Nessa última área, de aspecto frio, com poucas cores além de marrom, cinza e preto, instalaram-se mostruários de calçados e instrumentos de trabalho da classe operária. Acessórios rudes e grosseiros, opacos, sem bordados. A expressão da exploração, da desigualdade, dos maus-tratos da vida.

A temática e a narrativa da exposição temporária se originam de uma extensa pesquisa social, política e culturalmente engajada encabeçada por Alison Matthews David, uma das curadoras. Em 2015, ela publicou o livro Fashion Victims: The Dangers of Dress Past and Present, no qual aprofunda inúmeras questões tratadas na mostra do BSM.

Não me parece exagero afirmar, portanto, que a exposição Fashion Victims é uma experiência estética e ética na qual a exuberância e a morbidez desestabilizam nossas emoções. Ao vivenciá-la, facilmente se 
percebem paralelos entre a perversidade da moda do século XIX e a indústria de hoje, com casos notórios de exploração na produção têxtil. Por meio dos episódios narrados, é possivel ultrapassar a desqualificação reducionista frequentemente dirigida apenas a consumidores - ou melhor, a consumidoras - que sucumbem às tendências, deixando de criticar um sistema produtivo muito mais amplo e perverso e outras práticas danosas movidas por prazeres, riscos e abusos que estão para além da compra de produtos e serviços do universo das aparências.

\section{REFERÊNCIAS}

MATTHEWS DAVID, Alison; SEMMELHACK, Elizabeth. Fashion Victims: The Pleasures and Purils of Dress in the 19th Century. Toronto: Bata Shoe Museum, 2014.

MATTHEWS DAVID, Alison. Fashion Victims: The Dangers of Dress Past and Present. Londres: Bloomsbury, 2015. 